\title{
Employee Perceptions Of Diversity Management At A Tertiary Institution
}

\author{
C Harris \& GG Rousseau \\ Department of Industrial Psychology, Nelson Mandela Metropolitan University \\ DJL Venter \\ Department of Statistics, Nelson Mandela Metropolitan University
}

\begin{abstract}
Diversity is an inevitable aspect of organisational life, which has to be deal with at one time or other. How employees perceive diversity impacts on their behaviour and therefore managing it is imperative. The objective of this study was to investigate perceptions among staff members at a tertiary institution in the Eastern Cape of diversity management. A further aim was to assist the institution in developing ways to improve diversity management. A diversity management questionnaire was administered to employees to determine perceptions. Results confirmed that employees perceived a small number of diversity-related problems to be present. Employees believed that the university understood the value of change and that they were in the nondiscriminatory phase of evolution towards becoming multicultural. A follow-up study in this field is necessary.
\end{abstract}

JEL M51

\section{1}

\section{Introduction}

Diversity in the workplace is perceived by some employees as a stumbling block along their career path, irrespective of whether they are referring to the diversity of management, fellow employees or organisational departments. They epitomise the workplace as a laboratory and diversity as the poisonous chemicals being tossed into a single cauldron. This negative attitude amongst employees can be a recipe for disaster; a time bomb waiting to explode! To the contrary, diversity viewed from a positive perspective can create tremendous opportunity for an organisation. Innovation, improved decision-making and creativity are but a few of the possibilities (Robbins, 2005). Diversity should therefore not be viewed with pessimism, but rather be seen as a laboratory where wonders can be created when different chemicals are mixed.

With the above contradictory views at hand, it is imperative to increase awareness and knowledge of diversity and get rid of the myths on diversity that individuals hold. These myths along with attitudes towards management and how they behave towards others in the workplace mould peoples' perceptions, which in turn influence employee behaviour (Ivancevich \& Matteson, 1999). The motivation for this study lies in determining employees' perceptions of diversity management in an organisation, because the way in which employees perceive diversity and the management thereof will affect their work. Robbins (2000) states that perception is important to the study of organisational behaviour, because peoples' behaviour is based on their perception of what reality is and not always on reality itself. Behaviour is therefore driven by perceptions of reality.

Perception is the process by which individuals select, organise and interpret the input from their senses to give meaning and order to the world around them. Through perception, individuals try to make sense of their environment and the objects, events and other people in it (George \& Jones, 1999). Research on perception consistently 
demonstrates that different individuals may look at the same thing, yet perceive it differently. People interpret what they see and call it reality (Robbins, 2005). If a significant number of employees have negative perceptions regarding the effectiveness of diversity management, organisations need to focus on these perceptions regardless of their actual merits. Therefore, what people believe about the work environment is of vital importance regardless of whether or not these beliefs are consistent with the facts. To address the issue effectively it is necessary to improve the accuracy of employees' perceptions, a requirement for decisions that benefit the organisation and all its members (George \& Jones, 1999).

\subsection{Diversity and the management thereof}

The word "diversity" has become synonymous with the workforce and in an effort to remain competitive institutions need to capture the advantages of diversity. Cox (2001) mentioned that diversity is the variation of social and cultural identities among people existing together in a defined environment, such as work or school. Francesco and Gold (1998) define diversity as a range of differences, including gender, race, ethnicity, and age i.e. characteristics that may be apparent when looking at someone. Diversity also includes differences that are not visible, such as education, professional background, functional area of expertise, sexual preference and religion. All these differences are important as they affect employees' perceptions, which influence how employees behave within an organisation. Robbins (1998) defines workforce diversity as the increasing heterogeneity of organisations in terms of gender, race and ethnicity, with the inclusion of different groups. It is of vital importance that organisations recognise that they will encounter some form of diversity in the workplace. Whether diversity relates to gender, age, race, religion, sexual orientation, function, department and the like, diversity is unavoidable and therefore it is imperative to ensure that it is effectively managed.

Diversity management is the planning and implementation of organisational systems and practices to manage people so that the advantages of diversity are maximised while its disadvantages are minimised. The goal of managing diversity is to maximise the ability of all employees to contribute to organisational goals and achieve their full potential unhindered by group identities (Cox, 1994). Furthermore, managing diversity should incorporate the development of a working environment in which all employees, with their similarities and differences, can contribute to the strategic and competitive advantage of an organisation (Bulbulia, 2003). Diversity management should not be viewed as an isolated issue, because it touches every aspect of the organisation and should be integrated into all organisational processes.

How diversity is managed in an organisation will ultimately influence employees' attitudes and perceptions towards that organisation. Diversity, if positively managed, can increase creativity and innovation in organisations, as well as improve decision-making by providing different perspectives on problems. One can observe an increased competitiveness in positive shareholder gains for firms with highly effective diversity management programmes (Pandey, Shanahan \& Hansen, 2005). When diversity is not managed properly, there is potential for higher labour turnover, problematic communication and increased interpersonal conflicts (Robbins, 1998).

\subsection{Stages of organisational evolution towards diversity management}

\section{(a) Monocultural stage}

Cox (1994) describes organisations that are culturally and demographically homogenous as "monolithic." During this stage the organisation acts as though employees are the same. While staff may be diverse there is an expectation to conform to organisational standards and norms, that typically follow the "white male model". Women and people of colour are expected to assimilate and adopt the dominant style of the organisation, without any consideration of their own norms and values. This is a sign that management does notvalue diversity. Differences tend to be underplayed and management 
appears to be colour blind (Gardenswartz \& Rowe, 1993). This organisational type typically features high levels of occupational segregation, which finds men from racial minorities and women in low status jobs. Persons from minority culture backgrounds are not represented in the overall work population, as well as in the power structure of the organisation (Cox, 1994). This is a stage where much bias and discrimination occurs in the workplace.

\section{(b) Plural organisation}

Jackson and Holvina (cited in Gardenswartz \& Rowe, 1993) refer to the plural organisation as the non-discriminatory phase. This organisational type is generally more heterogeneous than the monolithic organisation. It is more accepting of persons from cultural backgrounds that differ from the dominant group i.e. women and people of colour are recruited and promoted. However, the problem of skewed representation across functions, organisational levels and workgroups, so typical of a monolithic organisation, remains evident in the plural organisation. As a result of government regulations and threat of employee grievances, organisations begin to pay attention to affirmative action requirements and equal employment opportunities regulations. Consideration at this stage is aimed at meeting quotas in hiring and promotion, not as a result of acceptance of others, but out of a need to comply with government legislation. Barriers that inhibit diverse groups from moving into or upward in an organisation are removed. The goal at this stage is to eliminate the unfair advantage of the majority group (Gardenswartz \& Rowe, 1993).

\section{(c) Multicultural stage}

Cox (1994) describes the third and final organisational type as the multicultural organisation. In this stage not only is there recognition of differences in culture, backgrounds, preferences and values, but a qualifying of these differences (Gardenswartz \& Rowe, 1993). New norms allow more leeway for employees to do things in their own way. Flexibility of organisational policies and procedures ensures that nobody is put at an exploitative advantage (Gardenswartz \& Rowe, 1993). Cox (1994) believes this is an organisation that fosters and practices diversity valuation, which is ingrained as a facet of organisational culture. Attitudinal and structural integration of women and people of colour is promoted through diversity education and equitable rewards. There is an absence of institutionalised cultural bias in human resource management systems and practices. For example, women are paid the same as men for equal work. The multicultural organisation represents a place in which differences are appreciated and used to gain a competitive advantage.

\subsection{Key issues affecting diversity management}

Key issues affecting the management of diversity according to Murrell and James (2001) include the "glass ceiling", discrimination, sexual harassment, affirmative action, mentoring, job interruptions, career mobility, part-time work and leaves of absence. Other issues include stereotyping and ethnocentrism (Newell, 2002). DuPont (1997) concurs and labels the barriers to sound diversity management as prejudice, stereotyping and discrimination. Factors that have been shown to influence the work-related outcomes for women and people of colour include overall corporate climate, gender discrimination, sexual harassment, occupational segregation and exclusion from mentoring opportunities (Murrell \& James, 2001). These factors hinder performance and have a marked impact on perceptions. Prejudice against people comes from a belief that one's own culture, race, class or group is superior. It evolves from the belief that one's own group is right, while all other are wrong (DuPont, 1997). This concept is better known as ethnocentrism, which incorporates both positive feelings towards one's own group and negative feelings towards others (Segall et al., 1999). Stereotypes have been responsible for much discrimination in the workplace, which has led to the origin of vast labour legislation. Organisations that discriminate are not only being unethical but may even face lawsuits.

Discrimination is the act of treating people differently, unequally and usually negatively because they are members of a particular 
group (DuPont, 1997). Two of the approaches that are used to tackle the problems of unfair discrimination in employment are offering equal opportunities and managing diversity. Equal opportunity suggests the solution is to treat everyone the same, regardless of gender, ethnicity, age, etc (Newell, 2002). It is the organisation's responsibility to offer equal opportunities to a diverse range of employees. According to Goss (cited in Price, 1997) two fundamental reasons for this are to develop human capital and to ensure that social justice takes place. Artificially blocking the progress of any one group, will result in less than optimal use of an organisation's human capital. It can be concluded that unfair discrimination is irrational, as it limits the resource value of employees. Goss continues by stating that organisations should have moral or ethical interest in social equality, wherein the economic benefits are secondary to this social duty. On the other hand, managing diversity emphasises treating everyone differently, in accordance with different circumstances and needs (Newell, 2002).

When equal employment opportunities are not offered, some of the above elements including prejudice, discrimination and stereotyping may form part of organisational life. These diversity barriers take place in the form of racist or sexist jokes, rude remarks or the refusal to hire or promote based on age or gender (DuPont, 1997). These are but a few of the symptoms of diversity-related problems that are visible in organisations today

\subsection{Diversity initiatives}

Programmes intended to value diversity may include diversity training, career development, human resource strategic planning, accountability in performance appraisals for attaining diversity-related goals and equality councils (Gilbert \& Ones, 1998). Training that reflects the specific needs of a diverse workforce can benefit everyone. Employees acquire skills and job satisfaction, while employers obtain a reliable, well-trained workforce (Gooley, 2000). However, diversity management must move beyond the isolated implementation of programmes like diversity training, to the development of a system-wide approach that involves the alignment of organisational culture, reward systems and policies and procedures (Hayes, Bartle \& Major, 2002: 445).

Annual cultural audits ensure that human resource systems are aligned with diversity valuation strategies and that they meet the needs of their diverse staff members. According to Galinsky (cited in Gilbert \& Ones, 1998), organisations that have changed their human resource policy to reflect the changing nature of the workforce, may reap benefits of increased loyalty, productivity and decreased labour turnover. Diversity can cause major conflict in the organisation and unless these conflicts can be resolved, much of the benefits of diversity will be lost. Among groups with a history of discrimination, there may be a heightened sensitivity to prejudice and a tendency to perceive unwanted feedback or confrontation as discriminatory (Gardenswartz \& Rowe, 1993). Walton (1994) mentions that in mixed cultural groups, conflict is often the result of communication problems. Organisations need to be aware of ways in which conflict for different cultures can be resolved, to ensure that the benefits of diversity always outweigh the disadvantages. Clarke and Lipp (1998) state that when people from different cultures understand each other's intentions and perceptions, they can learn to work together more harmoniously.

\subsection{Education}

At the dawn of the twenty-first century, it is generally accepted that diversity in higher education is a critical component that defines the quality and progressiveness of the education systems. It is an accepted fact that diversity increases opportunities for wider choice in programmes and institutional types for the ultimate benefit of the individual consumer and the general socio-economic good of the nation (Dyasi, 2001). Institutions of higher education have a major role to play in the South African environment to empower their employees. If managers at universities - whether academic or supporting, top management or lower level 
managers - do not accept the realities of the new South Africa and make the required internal modifications and manage diversity effectively, universities around the country will be unable to achieve their mission or objectives. For this reason, a study of diversity management at tertiary institutions in South Africa and especially universities is essential (Strydom \& Erwee, 1998).

\section{2}

\section{Method}

\subsection{Sample}

The target population for this study consisted of all employees working at the Nelson Mandela Metropolitan University (NMMU), approximately 2000 (according to the NMMU Human Resource department) who were listed on the NMMU payroll at 25 February 2005. This included academic, administrative, professional and technical employees.

\subsection{Research instrument}

The researcher aimed to determine individuals' perceptions of the present level of diversity management issues in the institution by way of a Diversity Management Questionnaire. The questionnaire was originally developed by Gardenswartz and Rowe in 1993 and later adapted by Erwee and Strydom (1998) for use in the South African context. It was then further refined by Erwee and Innes (1998) and shortened for use in Australia. In discussions with Erwee it was suggested that for the purpose of research in South Africa the shortened version of the questionnaire be used. One of the positive points of utilising this particular survey was that it would be quick and easy to administer. The questionnaire consists of approximately forty items regarding perceptions of diversity-related topics and are discussed per section below (View the questionnaire items in Appendix 1).

\section{(a) Symptoms of diversity-related problems}

Section A required respondents to indicate according to a five-point Likert scale, to what extent a specific symptom was present in their working environment. The objective of this section of the questionnaire was to identify diversity-related problems within the university. It was also intended to raise awareness of diversity-related issues (Gardenswartz \& Rowe, 1993). The focus was on the frequency with which problems were identified. In other words, when the same problems surfaced repeatedly respondents are sending a message. For example, if a large per centage of respondents perceive that there are barriers to promotion for diverse employees, one could conclude that this is a diversity-related problem. Furthermore, to determine the overall extent of diversityrelated problems as perceived by a respondent, a summated score was calculated for each respondent as the mean of responses to all the questions in Section A (note that item A1, the only positive statement, was inverted). This score was labelled Symptoms for purposes of reporting and interpretation. The closer the global mean score is to a value of one (five), the greater (lesser) the extent of the perceived problems.

\section{(b) Openness of the university culture to change}

The objective of section B of the questionnaire was to assess respondents' perceptions regarding the organisation's openness to change, to identify areas where it was not open and to determine what needs to be done in order to develop a more open and flexible organisational culture. Respondents were encouraged to share their opinion regarding change by rating the statements on a five-point Likert scale. Similar to what was done for Section A, a summated score labelled Openness was calculated for this section. Where necessary (items B7 and B14) were inverted in such a way that a high global mean score can be interpreted as an indication, as perceived by the respondents, of the institution's lack of an open culture conducive to the changes required to manage diversity effectively.

\section{(c) Current position of diversity management}

The objective of Section C of the questionnaire was to determine the organisation's stage of development in dealing with diversity. Is the institution monocultural, pluralist or 
multicultural? Organisations function at many levels simultaneously and evolve unevenly resulting in having some points in all the stages of development (Gardenswartz \& Rowe, 1993). Data from this section could provide clues to develop strategies on how organisational development may be implemented.

This section consisted of a series of items with a choice of three alternative statements for each item. Option 'a' corresponds to a monocultural organisation, and ' $b$ ' and ' $c$ ' to a pluralist and multicultural organisation respectively. Similar to what was done for the preceding sections, a summated score labelled Position was calculated for Section C. The global mean score and mode for Position is an indication of the perceived stage of the institution's development in dealing with diversity. A mean score between 1.0 and 1.67 implies a perceived monocultural institution, whereas a mean score between 1.68 and 2.33 is an indication of a pluralist institution in transition towards the multicultural goal required for the proper management of diversity, indicated by a global mean score between 2.34 and 3.0.

Two forms of validity were addressed with regard to the summated scores calculated in this study: face validity and content validity. Two human resource specialists assessed the questionnaire and both agreed that face validity was present. Another form of validity that was considered in this study is that of content validity. Does the questionnaire adequately address all the aspects of diversity management that it is supposed to measure? The aim is to determine whether all facets of a particular latent variable are adequately covered by the applicable statements within the questionnaire. The link between the items in the diversity management questionnaire and the information in the literature review indicated that content validity has been achieved. The reliability of the summated scores were determined by calculating Cronbach's coefficient alpha. Results are reported below.

\subsection{Data collection}

The diversity management survey consisted of a self-administered questionnaire, distributed to 400 employees with clear instructions on how to complete it. This allowed employees to do the survey at their own leisure and hand it back by the stipulated date. Respondents were granted one week to complete and return the survey. In total, 162 completed questionnaires were returned and captured. The demographics of the sample, as can be viewed in Table 1, indicate that the sample is in fact a diverse one i.e. it is heterogeneous and not homogenous.

\section{Table 1}

Frequency distribution of demographic variables of the sample

\begin{tabular}{|l|c|c|}
\hline Demographic variable & Frequency & Percentage \\
\hline Gender $(\mathrm{n}=162)$ & & \\
Male & 59 & $36 \%$ \\
Female & 103 & $64 \%$ \\
\hline Race $(\mathrm{n}=162)$ & & \\
White & 97 & $59.9 \%$ \\
Black & 37 & $22.8 \%$ \\
Coloured & 18 & $11.1 \%$ \\
Indian & 9 & $5.6 \%$ \\
Other & 1 & $0.6 \%$ \\
\hline
\end{tabular}




\begin{tabular}{|l|r|r|}
\hline Age $(\mathrm{n}=162)$ & & \\
$20-29$ yrs & 25 & $15.4 \%$ \\
$30-39$ yrs & 56 & $34.6 \%$ \\
$40-49$ yrs & 46 & $28.4 \%$ \\
$50-59$ yrs & 28 & $17.3 \%$ \\
60 yrs + & 7 & $4.3 \%$ \\
\hline Employee type $(\mathrm{n}=160)$ & & \\
Academic & 57 & $35.6 \%$ \\
Administrative & 74 & $46.3 \%$ \\
Technical / Support & 29 & $18.1 \%$ \\
\hline Appointment type $(\mathrm{n}=162)$ & 120 & \\
Permanent & 42 & $74.1 \%$ \\
Non-permanent & & $25.9 \%$ \\
\hline Highest qualification $(\mathrm{n}=160)$ & 22 & \\
Matric & 29 & $13.8 \%$ \\
Diploma & 23 & $18.1 \%$ \\
Degree & 80 & $14.4 \%$ \\
Post Graduate Degree & 6 & $50.0 \%$ \\
Other & & $3.8 \%$ \\
\hline Years of service $(\mathrm{n}=161)$ & 59 & \\
$0-5$ yrs & 40 & $36.6 \%$ \\
$6-10$ yrs & 36 & $24.8 \%$ \\
$11-15$ yrs & 26 & $16.2 \%$ \\
16 yrs + & & \\
\hline Management member $(\mathrm{n}=162)$ & & \\
Yes & & \\
No & & \\
& & \\
& & \\
\hline
\end{tabular}

\subsection{Data analysis}

BMDP Statistical Software Release 7.0 was used in the statistical analysis of the data, to calculate descriptive statistics such as the mean, standard deviation and median scores. It was furthermore used to calculate Cronbach's coefficient alphas for the summated scores, as well as to perform factor analysis. Analysis of variance (ANOVA) was utilised to determine the statistical significance of differences between demographic groups with regard to the summated scores.

\section{3}

\section{Results}

Reliability of the summated scores calculated in this study was determined by calculating Cronbach's coefficient alphas for the latent variable corresponding to each section of the questionnaire. In addition to this, principal components factor analysis was utilised to determine whether or not all the items in a particular section of the questionnaire were in fact necessary to calculate the applicable summated score or whether removing some 
of the items would make the scores more reliable i.e. improve the internal consistency. The results of the factor analyses for Section A (symptoms of diversity-related problems),
Section B (openness to change) and Section C (current position of diversity management) are reported in Table 2 .

Table 2

Factor Analysis of the diversity management questionnaire per section

\begin{tabular}{|c|c|c|c|c|c|c|c|c|}
\hline \multicolumn{3}{|c|}{$\begin{array}{l}\text { Symptoms of diversity-related } \\
\text { problems }\end{array}$} & \multicolumn{3}{|c|}{ Openness to change } & \multicolumn{3}{|c|}{$\begin{array}{l}\text { Current position of diversity } \\
\text { management }\end{array}$} \\
\hline Items & $\begin{array}{l}\text { Initial } \\
\text { factor }\end{array}$ & $\begin{array}{l}\text { Final } \\
\text { loading }\end{array}$ & Items & $\begin{array}{l}\text { Initial } \\
\text { factor }\end{array}$ & $\begin{array}{l}\text { Final } \\
\text { loading }\end{array}$ & Items & $\begin{array}{l}\text { Initial } \\
\text { factor }\end{array}$ & $\begin{array}{c}\text { Final } \\
\text { loading }\end{array}$ \\
\hline $\mathrm{A} 1$ & -0.035 & - & B1 & 0.348 & 0.343 & $\mathrm{C} 1$ & 0.084 & - \\
\hline $\mathrm{A} 2$ & 0.532 & 0.531 & B2 & 0.595 & 0.584 & $\mathrm{C} 2$ & 0.290 & - \\
\hline A3 & 0.699 & 0.698 & B3 & 0.265 & - & $\mathrm{C} 3$ & 0.610 & 0.608 \\
\hline A4 & 0.623 & 0.623 & B4 & 0.551 & 0.544 & $\mathrm{C} 4$ & 0.533 & 0.514 \\
\hline A5 & 0.506 & 0.505 & B5 & 0.730 & 0.727 & C5 & 0.759 & 0.758 \\
\hline A6 & 0.633 & 0.633 & B6 & 0.755 & 0.749 & $\mathrm{C} 6$ & 0.651 & 0.673 \\
\hline A7 & 0.664 & 0.663 & B7 & 0.340 & 0.352 & $\mathrm{C} 7$ & 0.278 & - \\
\hline A8 & 0.622 & 0.622 & B8 & 0.781 & 0.789 & C8 & 0.472 & 0.474 \\
\hline A9 & 0.692 & 0.693 & B9 & 0.623 & 0.632 & C9 & 0.466 & 0.475 \\
\hline A10 & 0.592 & 0.592 & B10 & 0.524 & 0.529 & C10 & 0.400 & 0.408 \\
\hline A11 & 0.715 & 0.716 & B11 & 0.611 & 0.605 & C11 & 0.663 & 0.660 \\
\hline A12 & 0.644 & 0.645 & B12 & 0.759 & 0.769 & & & \\
\hline A13 & 0.786 & 0.786 & B13 & 0.707 & 0.704 & & & \\
\hline A14 & 0.623 & 0.623 & B14 & 0.080 & - & & & \\
\hline A15 & 0.729 & 0.729 & B15 & 0.561 & 0.560 & & & \\
\hline $\mathrm{n}$ & 157 & 157 & $\mathrm{n}$ & 157 & 158 & $\mathrm{n}$ & 143 & 145 \\
\hline $\mathrm{C} \alpha$ & 0.88 & 0.89 & $\mathrm{C} \alpha$ & 0.84 & 0.86 & $\mathrm{C} \alpha$ & 0.68 & 0.71 \\
\hline$\%$ Var & $39.6 \%$ & $42.4 \%$ & $\%$ Var & $34.1 \%$ & $38.7 \%$ & $\%$ Var & $26.0 \%$ & $33.9 \%$ \\
\hline \multicolumn{8}{|c|}{$\mathrm{C} \alpha=$ Cronbach's coefficient alpha } & \\
\hline
\end{tabular}

Table 2 indicates that after omitting certain items from the set of items used to calculate the summated scores, adequate Cronbach's alphas (greater than the recommended $0.70)$ were obtained for each section of the questionnaire. Factor analysis has helped identify the weaknesses of the questionnaire by indicating which statements should be excluded to strengthen the reliability coefficients. This information is invaluable for future research within the context of this study.

These results are an indication of employee perceptions towards diversity management. The results have been divided into three 
sections based on the diversity management questionnaire. These are the symptoms of diversity-related problems (Section A), openness to change (Section B) and the current position of diversity management (Section C).

\subsection{Symptoms of diversity-related problems}

Section A addressed the symptoms of diversityrelated problems. The data presented in Table 3 relates to statements A1 to A15 in Section A of the questionnaire (see Appendix 1). The results are sorted so that those symptoms of diversityrelated problems perceived by respondents as most prevalent (A8) are at the top of the table and those perceived as least prevalent (A1) at the bottom. Note that item A1 was the only statement in Section A phrased positively and therefore inverse to the other statements in this section. Responses to A1 were inverted to obtain mean and median values that can be compared with the values calculated for the rest of the statements in Section A. The summated score Symptoms was categorised according to the following scheme: scores less than 2.6 labelled Present; scores between 2.6 and 3.4 inclusive labelled Neutral and scores greater than 3.4 labelled Not Present.

Table 3

Descriptive statistics for Section A Symptoms of diversity-related problems

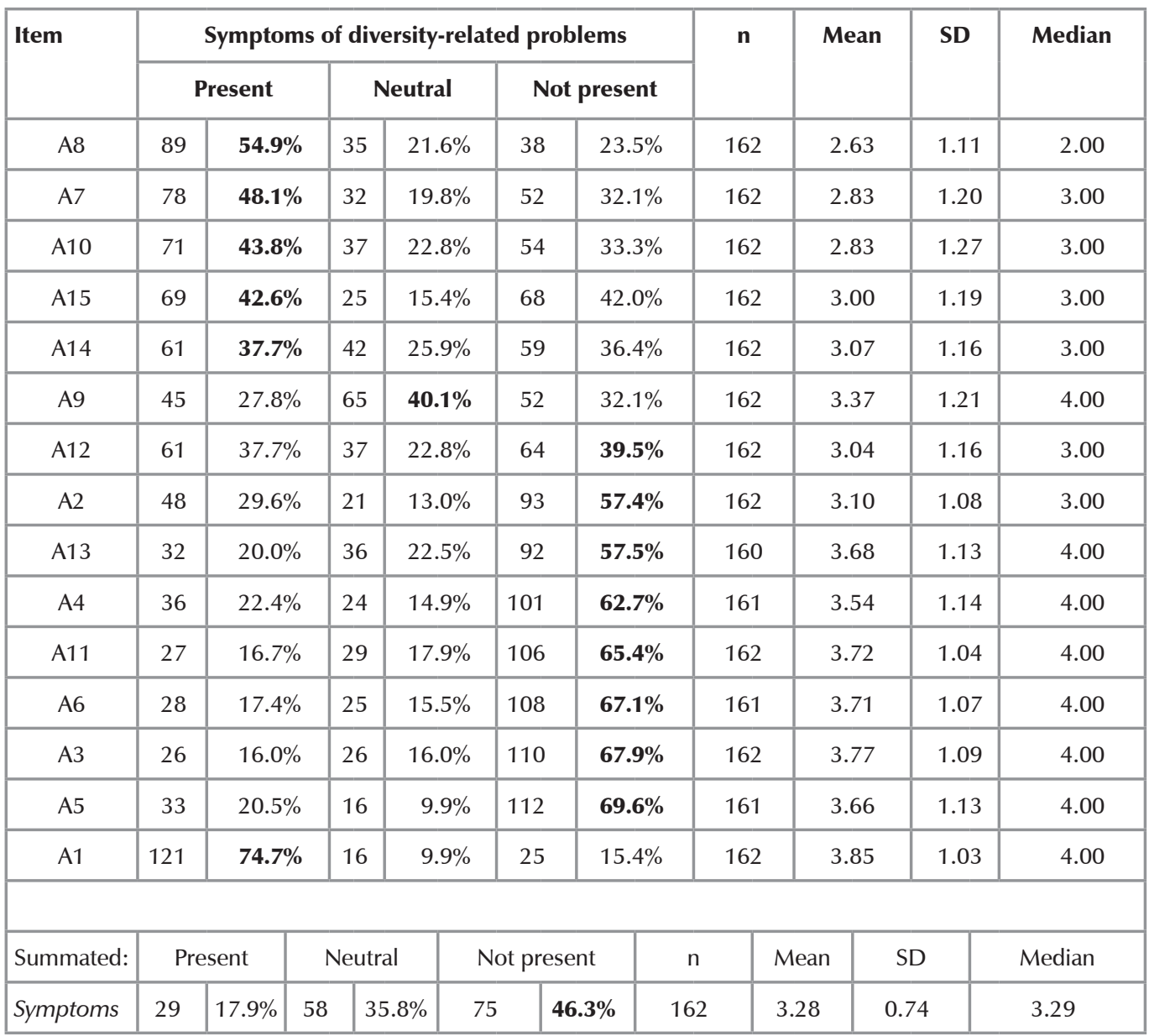




\section{(a) Major problems as perceived by respondents}

The results of the diversity management questionnaire confirmed that one of the biggest perceived problems at the university, is a lack of social interaction between members of diverse groups (statement A8). Even though employees may perceive there to be diversity amongst staff members at the university, respondents feel that this is ultimately on a formal work level and not on a social level. In other words, interaction between diverse groups in the institution appears to be institutionalised and not "personalised".

The second largest symptom of diversityrelated problems is that respondents perceive there to be complaints about discrimination in promotions, pay and performance reviews (statement A7). A large number of respondents (48.1 per cent) agreed with this statement, indicating that this may be the view of approximately half of NMMU staff members. Irrespective of whether this perception is true or not, the university needs to ensure that this issue is addressed. Perceptions about "perceived" differences could possibly impact negatively on employees' morale and satisfaction, always thinking that others doing the same job are better off than themselves.

The third most prevalent symptom of diversity-related problems is that more than two out of every five respondents (43.8 per cent) feel that the university is experiencing difficulty in recruiting and retaining members of different groups (statement A10). Perhaps this is a problem that the Human Resources and Transformation Department should take note of, as it appears that employees are feeling that not enough is being done to recruit and retain a diverse range of staff. One of the possibilities that needs to be considered is whether or not the unique needs of a diverse staff complement are being met. The above discussion referred to the three most prevalent symptoms of diversityrelated problems indicated by respondents. Other noteworthy symptoms reported by respondents were: frustrations resulting from cultural differences (A15) and barriers in promotion for diverse employees (statement A14).

\section{(b) Minor problems perceived by respondents}

A noticeable aspect of the results reported in Table 3 is that the majority of NMMU staff perceived certain symptoms of diversityrelated problems to be almost non-existent. Respondents perceived there to be little difficulty in communicating due to limited or heavily accented English (statement A5). This indicates that respondents perceive communication between different groups to be relatively effective and that if there were problems relating to communication, it was not as a result of limited or heavily accented English.

There also appears to be very little resistance to working with people from diverse groups (statement A3). This reiterates the notion that interaction and working in mixed groups is institutionalised at the university, but as noted earlier this is not the same for interaction of a social nature. Table 3 indicates that approximately two out of three respondents (67.1 per cent) perceived there to be no ethnic, racial or gender insults or jokes present in the organisation (statement A6). Respondents did not perceive there to be considerable open conflict between groups or individuals from different groups (statement A11). Although this may be the case, it does not necessarily mean that conflict does not occur. It just indicates that conflict of this nature is not being experienced by the majority of the NMMU staff members.

Finally, it is positive to note, as can be seen in Table 3, that staff perceived there to be diversity in staff composition, with 74.7 per cent of respondents agreeing that diversity is either present or present to a certain degree within the university (statement A1). The last entry in Table 3 reflects the statistics for the summated score for Section A. The mean score of 3.28 falls in the middle interval of 2.6 to 3.4 , thus indicating a relatively moderate evaluation of symptoms of diversity-related problems, further confirmed by the median score of 3.29. These results are an indication that although respondents appear to be non-aligned, they still perceive that there are a few diversity-related issues which need attention. 
As is evident from the above comments about symptoms of diversity-related problems, one can see that there are aspects within the parameters of diversity that staff members view as problematic. It is therefore justified to accept that staff perceive there to be problems as a result of diversity in the organisation. It is encouraging to note that even though staff perceive there to be problems within the organisation relating to diversity, they appear to see that there are "positives" that can be harnessed in the organisation as a result of diversity. A further encouraging result was that almost half (46.3 per cent) of the respondents recorded a summated Symptoms score greater than 3.4, putting them in the Not Present group, whilst the mean and median were both in the Neutral interval.

\section{(c) Openness to change}

Section B referred to the perceptions respondents had of the university's openness to change, ranging from accepting and valuing change to not being open to change at all. The data presented in Table 4 reflects answers to questions B1 to B15 in Section B of the diversity management questionnaire. Similar to what was done for Symptoms, the summated score Openness was categorised using cut-points of 2.6 and 3.4.

\section{Table 4}

Descriptive statistics for Section B Openness to change

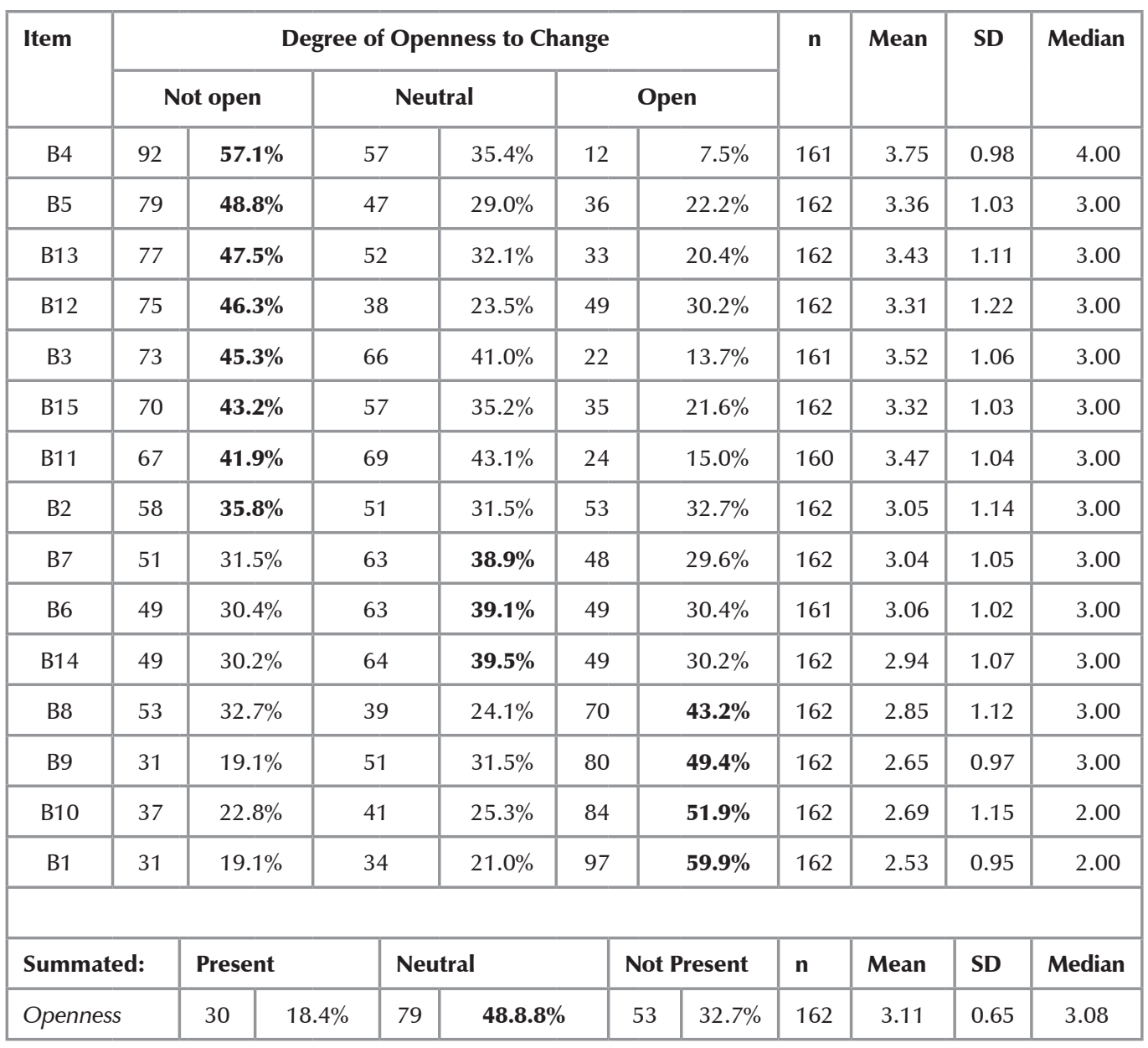


The results reflected in Table 4 with reference to response B4 suggest that the human resources department scored low on creativity in finding new ways to attract top talent from diverse groups. This aspect reiterates respondents' annoyance with the human resources department's inability to recruit a diverse range of qualified staff members for the institution. In addition to this, respondents believed that the university was not open to suggestions from all people in the organisation (responses to B5). This indicates that staff may feel that their valuable suggestions fall on deaf ears. Furthermore, respondents indicated that changes could not be brought about easily (responses to B13) in the university. This may be as a result of their responses in B5 showing that employees' ideas and suggestions are not valued. It also indicates that the university may be run in a bureaucratic manner, where decisions are made at the top, a lot of red-tape exists and the tradition of "this is the way things are done here" is entrenched.

Staff indicated that performance evaluations did not incorporate a measure for staff's adaptation to change (responses to B11). This could result in staff feeling that there is no point in adapting to change, as there was no reward linked to this aspect. Respondents also indicated that rewards given to performers are often generic and do not always match the preference of the individual being rewarded (responses to B3). One has to consider the implications this may have on retaining a diverse staff with diverse expectations. For example, all staff will not be motivated or satisfied to work hard or remain in the service of an organisation that does not reward them according to their wants and needs.

The following three issues (responses to B11, B3 and B4) relate to performance evaluation, rewards and recruitment that all relate to the Human Resources department. It is noticeable that staff members appear to be dissatisfied that this department is not proactive enough in dealing with diversity issues. The other two issues (responses to B5 and B13) relate to the university's willingness to change with the help and participation of employees. However, the respondents clearly indicate that they are not empowered to do so within the bigger framework of the university i.e. the university is not a participatory democracy.

On the positive side it can be seen in Table 4 (responses to B1), 59.9 per cent of respondents view change as a challenge and an opportunity, rather than an obstacle or problem. It is encouraging to note that change is viewed positively by employees. Furthermore (responses to B10), the largest proportion (51.9 per cent) of staff feel that their supervisor values their ideas and will ultimately implement good ideas and suggestions. On a micro level, in individual departments, respondents feel that they are being heard by their direct supervisors.

It appears that staff members (responses to B9) believe that training and services reflect an awareness of a diverse customer base. In other words, the university values diversity to the extent that it has become a part of the focus in training and service. As can be seen in Table 4, the global mean and median for the summated score Openness were 3.11 and 3.08 respectively, indicating a relatively neutral evaluation of openness to change. One should bear in mind that a global mean score of between 2.6 and 3.4 indicates that respondents feel that the organisation understands the value of change. However, they believe that there should be more openness to change and that the implementation thereof should be more rapid. If one bears in mind that openness to change is reflected by a mean of between 1.0 and 2.6, it is clear from the results in Table 4 that employees do not perceive the institution to be open to change.

\section{(d) Current position of diversity management}

Section $C$ of the questionnaire referred to the perceptions respondents had of the university's current position of diversity management. The data presented in Table 5 reflects the answers to questions $\mathrm{C} 1$ to $\mathrm{C} 11$ of the diversity management questionnaire. 
Table 5

Descriptive statisitics for Section C $\sim$ Current position of diversity management

\begin{tabular}{|c|c|c|c|c|c|c|c|c|c|c|c|}
\hline \multirow{2}{*}{$\begin{array}{l}\text { Item } \\
\text { C3 }\end{array}$} & \multicolumn{2}{|c|}{ Monocultural } & \multicolumn{3}{|c|}{$\begin{array}{c}\text { Non- } \\
\text { discriminatory }\end{array}$} & \multicolumn{2}{|c|}{ Multicultural } & \multirow{2}{*}{$\begin{array}{c}\mathbf{n} \\
162\end{array}$} & \multirow{2}{*}{$\begin{array}{r}\text { Mean } \\
1.83\end{array}$} & \multirow{2}{*}{$\begin{array}{l}\text { SD } \\
0.78\end{array}$} & \multirow{2}{*}{$\begin{array}{r}\text { Median } \\
2.00\end{array}$} \\
\hline & 65 & $40.1 \%$ & 59 & & $36.4 \%$ & 38 & $23.5 \%$ & & & & \\
\hline $\mathrm{C} 8$ & 61 & $39.9 \%$ & 44 & & $28.8 \%$ & 48 & $31.4 \%$ & 153 & 1.92 & 0.84 & 2.00 \\
\hline $\mathrm{C} 4$ & 47 & $29.2 \%$ & 69 & & $42.9 \%$ & 45 & $28.0 \%$ & 161 & 1.99 & 0.76 & 2.00 \\
\hline $\mathrm{C} 2$ & 62 & $39.0 \%$ & 75 & & $47.2 \%$ & 22 & $13.8 \%$ & 159 & 1.75 & 0.68 & 2.00 \\
\hline $\mathrm{C} 6$ & 43 & $27.0 \%$ & 83 & & $52.2 \%$ & 33 & $20.8 \%$ & 159 & 1.94 & 0.69 & 2.00 \\
\hline C11 & 16 & $10.2 \%$ & 84 & & $53.5 \%$ & 57 & $36.3 \%$ & 157 & 2.26 & 0.63 & 2.00 \\
\hline $\mathrm{C} 1$ & 2 & $1.2 \%$ & 91 & & $56.2 \%$ & 69 & $42.6 \%$ & 162 & 2.41 & 0.52 & 2.00 \\
\hline C10 & 44 & $28.2 \%$ & 45 & & $28.8 \%$ & 67 & $42.9 \%$ & 156 & 2.15 & 0.83 & 2.00 \\
\hline C9 & 53 & $33.5 \%$ & 33 & & $20.9 \%$ & 72 & $45.6 \%$ & 158 & 2.12 & 0.88 & 2.00 \\
\hline $\mathrm{C} 7$ & 29 & $18.4 \%$ & 54 & & $34.2 \%$ & 75 & $47.5 \%$ & 158 & 2.29 & 0.76 & 2.00 \\
\hline C5 & 38 & $23.5 \%$ & 34 & & $21.0 \%$ & 90 & $55.6 \%$ & 162 & 2.32 & 0.83 & 3.00 \\
\hline Summated: & & ocultural & & disc & $\begin{array}{l}\text { Non- } \\
\text { iminatory }\end{array}$ & $\mathrm{Mu}$ & cultural & $\mathrm{n}$ & Mean & SD & Median \\
\hline Position & 36 & $22.2 \%$ & & 74 & $45.7 \%$ & 52 & $32.1 \%$ & 162 & 2.06 & 0.46 & 2.12 \\
\hline
\end{tabular}

There appears to be much concern regarding responses in C2 of Table 5. Although a substantial number of respondents feel that there are flexible systems to accommodate the needs of diverse staff (47.2 per cent), some respondents (39 per cent) still feel that family and parenting problems are treated primarily as women's problems. This may be an indication that women are still perceived as caretakers and home makers and that they are not taken seriously in their efforts to ensue a career. Furthermore (responses to C3) many respondents (40.1 per cent) feel that new employees are expected to adapt to existing norms within the university, demonstrating monocultural tendencies. Staff members feel that new recruits are expected to "acclimatise" or conform to the norms and culture of the university, signifying inflexibility on the part of the university and the creation of a culture of "homogeneity". In addition to this (responses to C8), respondents perceive that a large amount of training time is spent on helping employees adapt to the university's culture and way of doing things (39.9 per cent). This once again reflects monocultural tendencies, where the university appears to be inflexible regarding the differences among staff. The responses in C8 reiterate the responses of $\mathrm{C} 3$, indicating that the university has created a culture of conformance to the norms, where staff members feel pressure to modify their own norms and values to harmonise with those of the university.

It is evident from Table 5 (responses to C1), that staff members do not seem to feel stifled by a formal organisational dress code, however it appears that they still dress within a conventional range. A relatively high mean of 2.41 , indicated a more multicultural approach, but as this is an ordinal scale it is more acceptable to focus on the median of 2.00 , indicating pluralist tendencies. It is positive to note that staff members feel that they have the freedom to express their individuality by what they wear. However, it still appears that the underlying organisational 
culture inhibits this to a small degree, as employees still tend to dress conservatively.

Furthermore, Table 5 indicates that one the most favourable aspects of the current position of diversity management (responses to C5) is that 55.6 per cent of respondents agree that dealing with diversity is part of every manager's job. Respondents appear to be prone to a multicultural view on this item with a mean of 2.32 and a median of 3.00. This is an indication that staff members feel that diversity should not be managed from top management down, but should filter throughout the organisation and each individual manager should be responsible for diversity issues that arise in his or her department. Table 5 refers to the degree of diversity in the organisational hierarchy (responses to $\mathrm{C} 7$ ) and in order to be a truly multicultural organisation, one should find diversity among staff at all levels. According to respondents (47.5 per cent) there appears to be diversity among staff at lower and middle levels only, indicating pluralist non-discriminatory tendencies. Staff members appear to feel that there is a need for diversity at higher levels of the organisation, such as having people of colour and women in top management positions.

Respondents agreed that managers are held accountable for working effectively with a diverse range of staff (responses to C9), which is so typical of a multicultural organisation. Staff members expect the head of the department to be responsible for administering his department effectively. He should involve his subordinates and in so doing create good working relationships and maintain a certain level of harmony. Table 5 indicates global mean and median summated Position scores of 2.06 and 2.12 respectively for Section $C$ of the questionnaire which indicates that the respondents perceive the institution to be evolving from a non-discriminatory phase towards multicultural.

\subsection{Differences between demographic variables in the sample}

To determine the relationship between the demographic variables and the summated scores of Sections A, B and C, ANOVAs were utilised. The results of the ANOVA are reported in Table 6. Statistically significant results are in bold. Table 6 indicates that none of the demographic variables was related to the latent variable Symptoms measured by the items in Section A. The latent variable Openness based on the Section B items was found to be significantly related to respondents' highest qualification and their appointment type, while Position, the latent variable for Section $\mathrm{C}$, was found to be related to home language, appointment type and membership of management.

\section{Table 6}

ANOVA table for demographic variables

\begin{tabular}{|l|l|c|c|c|c|c|}
\hline Variable & Source & S.S & D.F. & M.S & F-stat. & p-value \\
\hline \multirow{4}{*}{$\begin{array}{l}\text { Section A: } \\
\text { Symptoms }\end{array}$} & Home language & 0.460 & 2,134 & 0.230 & 0.43 & 0.650 \\
\cline { 2 - 7 } & Employee type & 0.817 & 2,134 & 0.408 & 0.77 & 0.466 \\
\cline { 2 - 7 } & Highest qualification & 0.206 & 3,134 & 0.069 & 0.13 & 0.943 \\
\cline { 2 - 7 } & Appointment type & 0.107 & 1,134 & 0.107 & 0.20 & 0.654 \\
\cline { 2 - 7 } & Management & 0.415 & 1,134 & 0.415 & 0.78 & 0.379 \\
\cline { 2 - 7 } & ERROR & 71.265 & 134 & 0.532 & & \\
\hline
\end{tabular}




\begin{tabular}{|c|c|c|c|c|c|c|}
\hline \multirow{6}{*}{$\begin{array}{l}\text { Section B: } \\
\text { Openness }\end{array}$} & Home language & 1.750 & 2,134 & 0.875 & 2.40 & 0.095 \\
\hline & Employee type & 2.111 & 2,134 & 1.055 & 2.89 & 0.059 \\
\hline & Highest qualification & 3.567 & 3,134 & 1.189 & 3.26 & 0.024* \\
\hline & Appointment type & 5.861 & 1,134 & 5.861 & 16.05 & $\mathbf{0 . 0 0 0 * *}$ \\
\hline & Management & 0.449 & 1,134 & 0.449 & 1.23 & 0.269 \\
\hline & ERROR & 48.922 & 134 & 0.365 & & \\
\hline \multirow{6}{*}{$\begin{array}{l}\text { Section C: } \\
\text { Position }\end{array}$} & Home language & 2.394 & 2,134 & 1.197 & 6.74 & $0.002 * *$ \\
\hline & Employee type & 0.232 & 2,134 & 0.116 & 0.65 & 0.521 \\
\hline & Highest qualification & 0.314 & 3,134 & 0.105 & 0.59 & 0.623 \\
\hline & Appointment type & 1.332 & 1,134 & 1.332 & 7.50 & $0.007^{* *}$ \\
\hline & Management & 1.279 & 1,134 & 1.279 & 7.21 & $0.008^{* *}$ \\
\hline & ERROR & 23.785 & 134 & 0.178 & & \\
\hline \multicolumn{7}{|c|}{$*=p \leq 0.05$} \\
\hline
\end{tabular}

Post-hoc Scheffé tests were conducted to determine the statistical significance of betweengroup differences for the demographic variables with three or more categories that were found to be significantly related to the latent variables. The relevant p-values are reported in Table 7; significant values are in bold.

Table 7

Post-hoc Scheffé test p-values

\begin{tabular}{|c|c|c|c|c|}
\hline \multicolumn{5}{|c|}{ Highest qualification and Openness } \\
\hline Category & 1 & 2 & 3 & 4 \\
\hline 1 Matric & & .215 & .120 & .107 \\
\hline 2 Diploma & .215 & & .979 & 1.000 \\
\hline 3 Degree & .120 & .979 & & .957 \\
\hline 4 Post-grad & .107 & 1.000 & .957 & \\
\hline \multicolumn{5}{|c|}{ Home language and Position } \\
\hline Category & 1 & 2 & 3 & \\
\hline 1 English & & $.020 *$ & .975 & \\
\hline 2 Afrikaans & $.020 *$ & & .053 & \\
\hline 3 Xhosa & .975 & .053 & & \\
\hline
\end{tabular}


It is clear from Table 7 that no significant between-group differences were found for Highest qualification, whilst for Home language significant differences in Position mean scores were found between the Afrikaans and English groups and the Afrikaans and Xhosa groups.

Descriptive statistics for the significant demographic variables as well as Cohen's d statistics reflecting the practical significance of differences are reported in Table 8.

\section{Table 8}

Between-group differences for statistically significant results according to ANOVA

\begin{tabular}{|c|c|c|c|c|c|c|c|c|}
\hline \multirow[t]{2}{*}{ Variable } & \multirow[t]{2}{*}{ Highest qualification\# } & \multirow[t]{2}{*}{$\mathbf{n}$} & \multirow[t]{2}{*}{ Mean } & \multirow[t]{2}{*}{ S.D. } & \multicolumn{4}{|c|}{ Cohen's d } \\
\hline & & & & & & 1 & 2 & 3 \\
\hline \multirow{4}{*}{$\begin{array}{l}\text { Section B: } \\
\text { Openness }\end{array}$} & 1 Matric & 22 & 2.78 & 0.49 & 1 & & 0.75 & 0.79 \\
\hline & 2 Diploma & 29 & 3.19 & 0.60 & 2 & 0.75 & & 0.11 \\
\hline & 3 Degree & 23 & 3.26 & 0.70 & 3 & 0.79 & 0.11 & \\
\hline & 4 Post-graduate & 80 & 3.17 & 0.67 & 4 & 0.66 & 0.03 & 0.13 \\
\hline \multicolumn{9}{|c|}{$\#$ - none of the differences were significant according to Scheffé test } \\
\hline \multirow[t]{2}{*}{ Variable } & \multirow[t]{2}{*}{ Appointment type } & \multirow[t]{2}{*}{$\mathbf{n}$} & \multirow[t]{2}{*}{ Mean } & \multirow[t]{2}{*}{ S.D. } & \multicolumn{4}{|c|}{ Cohen's d } \\
\hline & & & & & & 1 & 2 & \\
\hline \multirow{2}{*}{$\begin{array}{l}\text { Section B: } \\
\text { Openness }\end{array}$} & 1 Permanent & 120 & 3.20 & 0.64 & 1 & & 0.55 & \\
\hline & 2 Non-permanent & 42 & 2.85 & 0.64 & 2 & 0.55 & & \\
\hline \multirow[t]{2}{*}{ Variable } & \multirow[t]{2}{*}{ Home language\# } & \multirow[t]{2}{*}{$\mathbf{n}$} & \multirow[t]{2}{*}{ Mean } & \multirow[t]{2}{*}{ S.D. } & \multicolumn{4}{|c|}{ Cohen's d } \\
\hline & & & & & & 1 & 2 & 3 \\
\hline \multirow{3}{*}{$\begin{array}{l}\text { Section C: } \\
\text { Position }\end{array}$} & 1 English & 70 & 2.01 & 0.44 & 1 & & 0.51 & 0.21 \\
\hline & 2 Afrikaans & 57 & 2.33 & 0.42 & 2 & 0.51 & & 0.69 \\
\hline & 3 Xhosa & 31 & 1.91 & 0.50 & 3 & 0.21 & 0.69 & \\
\hline \multicolumn{9}{|c|}{ \# - the difference between English and Xhosa groups was not significant according to Scheffé test } \\
\hline \multirow[t]{2}{*}{ Variable } & \multirow[t]{2}{*}{ Appointment type } & \multirow[t]{2}{*}{$\mathbf{n}$} & \multirow[t]{2}{*}{ Mean } & \multirow[t]{2}{*}{ S.D. } & \multicolumn{4}{|c|}{ Cohen's d } \\
\hline & & & & & & 1 & 2 & \\
\hline \multirow{2}{*}{$\begin{array}{l}\text { Section C: } \\
\text { Position }\end{array}$} & 1 Permanent & 120 & 2.03 & 0.48 & 1 & & 0.26 & \\
\hline & 2 Non-permanent & 42 & 2.14 & 0.36 & 2 & 0.26 & & \\
\hline
\end{tabular}




\begin{tabular}{|l|l|l|r|l|l|l|l|}
\hline Variable & Management & n & Mean & S.D. & \multicolumn{2}{|l|}{ Cohen's d } \\
\cline { 4 - 8 } & & & & & & 1 & 2 \\
\hline $\begin{array}{l}\text { Section C: } \\
\text { Position }\end{array}$ & 1 Yes & 21 & 2.19 & 0.43 & 1 & & $\mathbf{0 . 3 4}$ \\
\cline { 2 - 8 } & 2 No & 135 & 2.04 & 0.45 & 2 & $\mathbf{0 . 3 4}$ & \\
\hline
\end{tabular}

Most of the Cohen's d statistics were greater than the threshold value of 0.20 thus confirming the practical significance of between-group differences for all demographic variables found statistically significant according to ANOVA and, where applicable, Scheffé tests, except for the Openness mean score, differences among Diploma, Degree and Post-graduate groups.

Considering the observed mean scores for the various demographic categories, the following conclusions can be made:

a) Highest qualification and Openness: Employees with matric are less positive about the openness of the university culture to change. A possible explanation for this result is that employees who have tertiary education have a more complete understanding of the change process, compared to employees who only have matric.

b) Appointment type and Openness: Employees with permanent appointments are more positive than their non-permanent colleagues about the openness of the university culture to change. This result could be attributable to the fact that permanent employees have job security, therefore viewing the university in a positive manner, whilst contract workers view the university in a negative manner possibly because their employment is constantly plagued by the threat of job loss.

c) Home language and Position: Afrikaans employees perceive the current position of the diversity management at the university as non-discriminatory, while their English and Xhosa colleagues regard it as monocultural. This implies that Afrikaans employees are of the opinion that the university has made more progress with its transformation process than what is believed by the other major language groups. d) Appointment type and Position: Employees with permanent appointments are more negative about the current position of diversity management at the university.

e) Management membership and Position: Members of management are more positive about the current position of diversity management at the university. This result is to be expected as management tend perceive their policies and procedures to be diversity-friendly.

\section{4}

\section{Limitations and future research recommendations}

The first limitation of the research is that it took place in a tertiary institution and therefore is likely to be applicable only to other tertiary institutions. Secondly, with the merger of the University of Port Elizabeth, Port Elizabeth Technikon and the Port Elizabeth Vista campus, there was a concern that factors such as a decreased morale, dissatisfaction, low motivation, uncertainty and ambiguity may have a negative bearing on individuals' perceptions. These are some of the factors that need to be taken into consideration when referring to the research findings of the present study, because results should be viewed within the relevant context.

Directions for future research could focus on how employee perceptions affect their work. This would give insight into the employee's mindset and link perception to work behaviours. Focus groups, a qualitative research tool, may enhance the research in the future by gaining insight about the underlying factors and reasons for employee perceptions. This research has attempted to gain insight into the perceptions of staff within the Nelson Mandela Metropolitan University, however little is known about the 
perceptions of students regarding diversity management within the university. This may be an area of interest for researchers wanting to pursue other avenues of this study.

\section{5}

\section{Conclusion}

A multicultural organisation is typically characterised by a culture that values diversity, pluralism, acculturation, full integration of nonmajority members (formally and informally), an absence of bias in management systems and a minimum of intergroup conflict (Cox, 1994). Employee perceptions have indicated that the university still needs to address some of these issues in order to become truly multicultural. Even though the university is perceived as understanding the value of change, employees feel that there is a greater need for openness and speedier implementation. Dealing with diversity is an evolutionary process. Transformation does not occur instantaneously and no organisation can have a homogenous workforce one week and a diverse workforce the next. Evolution is a gradual process of change that involves a shift in not only the demographics but also in the attitudes, perceptions, procedures, practices and policies within an organisation (Gardenswartz \& Rowe, 1993: 274).

Tertiary institutions in and around South Africa need to heed the call to celebrate the multitude of differences between people. Employees should be seen through new eyes... as assets to the organisation... as the fragrant spices that give flavour to the institution... and as the competitive advantage that give organisations the edge. Organisations should also remember that they should not only view their employees in this light, but should also manage the organisation to bring out the best in their diverse workforce. The NMMU needs to create a diversity-friendly environment to cater for the needs of its diverse staff complement. Managers must also recognise that employees often act based on their perceptions and not reality. For this reason it is imperative that management is aware of how employees perceive policies, practices, procedures and the management of diversity within the university. An organisation's ability to create a culture in which diversity is acknowledged, valued and effectively managed is more likely to have a positive effect on an organisation's bottom line (Friday \& Friday, 2003). Therefore if organisations are hoping to be successful, they should take heed of the above "warnings" to be aware of, value and manage diversity. In order to do so, organisations should pay close attention to employees' perceptions of diversity and diversity management.

\section{References}

1 BUlbuliA, S. (2003) "Diversity: Too hot to handle?", http://www.biz-community.com/ Article/196/18/2501.html (Accessed 11 May 2005).

2 CLARKE, C.C. \& LIPP, G.D. (1998) "Conflict resolution for contrasting cultures”, Training and Development, 52: 21-33.

3 COX, T. (1994) "Cultural diversity in organisations: Theory, research and practice", Berrett-Koehler: San Francisco.

4 COX, T. (2001) "Creating the multicultural organisation”, Jossey-Bass: San Francisco.

5 DUPONT, K. (1997) "Handling diversity in the workplace: Communication is the key", American Media Publishing: Iowa.

6 DYASI, M.M. (2001) "Diversity in higher education: The case of post apartheid South Africa", Proceedings of the 23rd EAIR Forum, 8-12 September, Porto.

7 ERWEE, R. \& INNES, P. (1998) "Diversity management in Australian companies: Compliance or conviction?", Proceedings of the ANZAM Conference, December, Adelaide.

8 FRANCESCO, A.M. \& GOLD, B.A. (1998) International Organisational Behaviour: Texts, Readings, Cases and Skills, Prentice-Hall: New Jersey.

9 FRIDAY, E. \& FRIDAY, S.S. (2003) "Managing diversity using a strategic planned change approach", Journal of Management Development, 22 (10): 863-880, http://www.uwc.ac.za (Accessed 11 May 2005).

10 GARDENSWARTZ, L. \& ROWE, A. (1993) "Managing diversity: A complete desk reference and planning guide", Co-published by Business One Irwin / Pfeiffer \& Company: New York.

11 GEORGE, J.M. \& JONES, G.R. (1999) "Understanding and managing organisational 
behaviour", (2 $2^{\text {nd }}$ ed.) Addison Wesley Longman, Massachusetts.

12 GILBERT, J.A. \& ONES, D.S. (1998) "Role of informal integration in career advancement: Investigation in plural and multicultural organisations and implications for diversity valuation", Sex roles: A journal of research, http:// www.findarticles.com (Accessed 3 April 2003).

13 GOOLEY, T.B. (2000) "A world of difference", Logistics Management Distribution Report, June, http://www.findarticles.com (Accessed 14 April 2003).

14 HAYES, B.C., BARTLE, S.A. \& MAJOR, D.A. (2002) "Climate for opportunity: A conceptual model”, Human Resource Management Review, 12(3): 445-468, http://sciencedirect.com (Accessed 17 March 2005).

15 IVANCEVICH, J.M. \& MATTESON, M.T. (1999) Organisational Behaviour and Management $\left(5^{\text {th }} \mathrm{ed}\right.$.) Irwin McGraw-Hill: Boston.

16 MURREL, J. \& JAMES, E.H. (2001) “Gender and diversity in organisations: Past, present and future directions", Sex roles: A journal of research, http://www.findarticles.com (Accessed 3 April 2003).

17 NEWELL, S. (2002) Creating the Healthy Organisation: Well-Being, Diversity and Ethics at Work, Thomson Learning: London.

18 PANDEY, V.K.; SHANAHAN, K.J. \& HANSEN, S.W. (2005) "The relationship between shareholder wealth effects, diversity and publicity as a marketing strategy", Journal of the Academy of Marketing Science, 77(4), 423-431.

19 PRICE, A. (1997) "Human resource management in a business context”, International Thomson Business Press: London.

20 ROBBINS, S.P. (1998) Organisational Behaviour: Concepts, Controversies and Applications, Prentice Hall International: New Jersey.

21 ROBBINS, S.P. (2000) Organisational Behaviour ( $9^{\text {th }}$ ed.) Prentice-Hall: New Jersey.

22 ROBBINS, S.P. (2005) Essentials of Organisational Behaviour ( $8^{\text {th }}$ ed.) Pearson Prentice Hall: New Jersey.

23 SEGALL, M.H., DASEN, P.R.; BERRY, J.W. \& POORTINGA, Y.H. (1999) Human Behaviour in Global Perspective: An Introduction to CrossCultural Psychology (2 $2^{\text {nd }}$ ed.) Allyn and Bacon: Boston.

24 STRYDOM, J.B. \& ERWEE, R. (1998) "Diversity management in a South African university: A case study”, Journal of Industrial Psychology, 24 (2), 914.

25 WALTON, S.J. (1994) "Cultural diversity in the workplace”, IRWIN Professional Publishing: Massachusetts.

WEBSITE VIEWED:

26 NELSON MANDELA METROPOLITAN UNIVERSITY WEBSITE., http://www.nmmu. ac.za (Accessed 11 May 2005). 


\section{Appendix 1}

The items presented in Appendix 1 reflect the statements from the diversity management questionnaire.

\section{Section A: Symptoms of diversity-related problems}

\begin{tabular}{|l|l|}
\hline A1 & Diversity in the staff composition \\
\hline A2 & Complaints about staff speaking other languages at work \\
\hline A3 & Resistance to working with other groups (ethnic, gender, physical ability) \\
\hline A4 & Difficulty in communicating due to limited or heavily accented foreign language \\
\hline A5 & Difficulty in communicating due to limited or heavily accented English \\
\hline A6 & Ethnic, racial or gender insults or jokes \\
\hline A7 & Complaints about discrimination in promotions, pay and performance reviews \\
\hline A8 & Lack of social interaction between members of diverse groups \\
\hline A9 & Increase in grievances by members of minority groups \\
\hline A10 & Difficultly in recruiting and retaining members of different groups \\
\hline A11 & Open conflict between groups or individuals from different groups \\
\hline A12 & Mistakes and productivity problems due to staff not understanding directions \\
\hline A13 & Exclusion of people who are different from others \\
\hline A14 & Barriers in promotion for diverse employees \\
\hline A15 & Frustrations resulting from cultural differences \\
\hline
\end{tabular}

\section{Section B: Openness to change}

\begin{tabular}{|l|l|}
\hline B1 & Change is viewed as a challenge and opportunity. \\
\hline B2 & Policies are reviewed annually. \\
\hline B3 & Rewards are handed out to suit the preference of the person rewarded. \\
\hline B4 & Our human resource department is creative in finding new ways to attract top talent among diverse groups. \\
\hline B5 & There is an openness to suggestions from all people in the company. \\
\hline B6 & Our strategic plan is revised as needed. \\
\hline B7 & "We have always done it this way" is a reflection on how our company responds to new ideas. \\
\hline B8 & When problems emerge, there is a willingness to fix them. \\
\hline B9 & Our training and services reflect awareness of a diverse customer base. \\
\hline B10 & My supervisor values new ideas and implements them quickly. \\
\hline B11 & Performance evaluation here measures staff's adaptation to change. \\
\hline B12 & Our top managers are visionary and approachable. \\
\hline
\end{tabular}




\begin{tabular}{|l|l|}
\hline B13 & We can bring changes about very easily \\
\hline B14 & There is little variation in style of dress among staff \\
\hline B15 & People at all levels can build or refine structures \\
\hline
\end{tabular}

\section{Section C: Current position of diversity management}

\begin{tabular}{|c|c|}
\hline C1 & $\begin{array}{l}\text { There is a standard way to dress and look. } \\
\text { There is no dress code, but most staff dress within a conventional range. } \\
\text { There is much variety in employees' style of dress. }\end{array}$ \\
\hline $\mathrm{C} 2$ & $\begin{array}{l}\text { Family and parenting problems like day-care and death of relatives are treated as women's problems. } \\
\text { There are flexible systems to accommodate the needs of diverse staff. } \\
\text { Many options are available to support staff with children and dependents. }\end{array}$ \\
\hline C3 & $\begin{array}{l}\text { Newcomers are expected to adapt to existing norms. } \\
\text { There is some flexibility to accommodate the needs of diverse staff. } \\
\text { Norms are flexible enough to include everyone. }\end{array}$ \\
\hline $\mathrm{C} 4$ & $\begin{array}{l}\text { Diversity is an issue that stirs irritation and resentment. } \\
\text { Attention is paid to meeting equal employment opportunity guidelines. } \\
\text { Working towards a diverse staff is seen as a strategic advantage. }\end{array}$ \\
\hline C5 & $\begin{array}{l}\text { Dealing with diversity is not a top priority. } \\
\text { Dealing with diversity is the responsibility of the Personnel Department. } \\
\text { Dealing with diversity is considered part of every manager's job. }\end{array}$ \\
\hline C6 & $\begin{array}{l}\text { People downplay or ignore differences among employees. } \\
\text { People tolerate differences and the needs they imply. } \\
\text { People value differences and they want to see diversity cultivated. }\end{array}$ \\
\hline C7 & $\begin{array}{l}\text { There is diversity among staff at lower levels. } \\
\text { There is diversity among staff at lower and middle levels. } \\
\text { There is diversity among staff at all levels. }\end{array}$ \\
\hline C8 & $\begin{array}{l}\text { More time is spent on training programmes to help employees: } \\
\text { adapt to our university's culture to learn the way we do things here. } \\
\text { develop diverse staff's ability to move up the company ladder. } \\
\text { communicate effectively across gender and cultural barriers. }\end{array}$ \\
\hline C9 & $\begin{array}{l}\text { Managers are held accountable for: } \\
\text { motivating staff to increase productivity. } \\
\text { avoiding equal opportunity and discrimination grievances. } \\
\text { working effectively with a diverse staff. }\end{array}$ \\
\hline C10 & $\begin{array}{l}\text { Managers are held accountable for: } \\
\text { maintaining a stable staff and existing norms. } \\
\text { meeting affirmative action goals and identifying promotable talent. } \\
\text { building productive work teams with staff. }\end{array}$ \\
\hline C11 & $\begin{array}{l}\text { In our university it is an advantage: } \\
\text { to be a white male. } \\
\text { to follow my boss's instructions. } \\
\text { to be unique and find new ways of doing things. }\end{array}$ \\
\hline
\end{tabular}

